\title{
Strengthening and load test of the upper-choir of the Pópulo Church in Braga, Portugal
}

Received (in revised form): 27th December, 2006

\section{João Guedes}

holds a Degree of Civil Engineering from the Faculty of Engineering of the University of Porto (FEUP), Portugal; MSc in Structural Mechanics Applied to Civil Engineering (FEUP); and PhD in Civil Engineering (FEUP). He is Assistant Professor at the FEUP and carries out research and practice on ancient stone masonry structures: maintenance and strengthening. He is technical adviser on heritage constructions in the structural domain under protocols with public and private institutions, namely the General Directorate for Buildings and Monuments (DGEMN) and the Portuguese Institute of Architectural Heritage (IPPAR).

\section{Aníbal Costa}

holds a Degree of Civil Engineering from the Faculty of Engineering of the University of Porto (FEUP), Portugal; MSc in Structural Mechanics Applied to Civil Engineering (FEUP); PhD in Civil Engineering (FEUP). He is Full Professor at the University of Aveiro, Portugal and carries out research and practice on seismic structural behaviour, on earth and stone masonry structures: maintenance and strengthening, with several articles published in these areas. He is technical adviser on heritage constructions in the structural domain under protocols with public and private institutions, namely the DGEMN and the IPPAR.

\section{Esmeralda Paupério}

holds a Degree of Civil Engineering from the Faculty of Engineering of the University of Porto (FEUP), Portugal. She is an Engineer at the Construction Institute at the FEUP and is technical adviser on rehabilitation and strengthening on ancient structures. She has extensive work experience on expert inspections on recent and old buildings for public and private institutions, namely the DGEMN and the IPPAR.

Correspondence: João Guedes, Faculty of Engineering, Department of Civil Engineering, University of Porto, Porto, Portugal; Tel: + 35122508 1887; Fax: + 35122508 1835; E-mail: jguedes@fe.up.pt

\begin{abstract}
This paper presents the structural intervention on the Pópulo Church in Braga, Portugal, a stone and brick masonry church dating from the 16th century, carried out by the Regional Directorate for Northern Buildings and Monuments of Portugal - DREMN - under the technical consultancy of the Nucleus for the Conservation and Rehabilitation of Buildings and Built Heritage - NCREP - of the Faculty of Engineering of Porto University - FEUP. During the restoration works, important deformations were detected in the upper-choir vault that involved structural intervention, namely numerical studies and in situ load tests. Besides describing the intervention process, the paper underlines that renovation works carried out in old structures, although previously planned and projected according to the available data, may suffer relevant modifications during the preparation and implementation procedures, which must be regarded as part of the intervention process. In particular, this work describes the in situ testing of the upper-choir vault to evaluate its vertical loading capacity and the final adopted strengthening solution.
\end{abstract}

Journal of Building Appraisal (2007) 3, 144-154. doi:10.1057/palgrave.jba.2950064

\section{Keywords:}

masonry, vaults, strengthening, load tests 


\section{INTRODUCTION}

The Pópulo Church, dating back to the late 16th century (Figure 1), is located in Braga, Portugal, and is made of masonry walls and vaults. Above the main entrance and over part of the church nave there is an intermediate level, the upper-choir, which is also supported by a vault. The vaults surface is divided into square frames made of granite elements in relief. The inside of the squares is covered with mortar and painted in white. Most of the walls are either covered with mortar and painted in white or covered with tiles. The façade is made of regular granite masonry.

During the late 1990s, the square in front of the façade of the church went through major works for the construction of an underground parking structure, which changed the soil conditions around the foundations of the church. This, and possibly other reasons that are beyond the scope of this study, led to important deformations on the upper-choir vault. In this context, the Nucleus for the Conservation and Rehabilitation of Buildings and Built Heritage (NCREP) was requested by the Regional Directorate for Northern Buildings and Monuments of Portugal (DREMN) to analyse these deformations, to decide on the need for repair and to present the best structural renovation strategy.

\section{PROBLEM PRESENTATION AND STRUCTURE DESCRIPTION}

During minor restoration works carried out at the Pópulo church, DREMN detected relevant deformations at the upper-choir vault (Figure 2). These deformations were

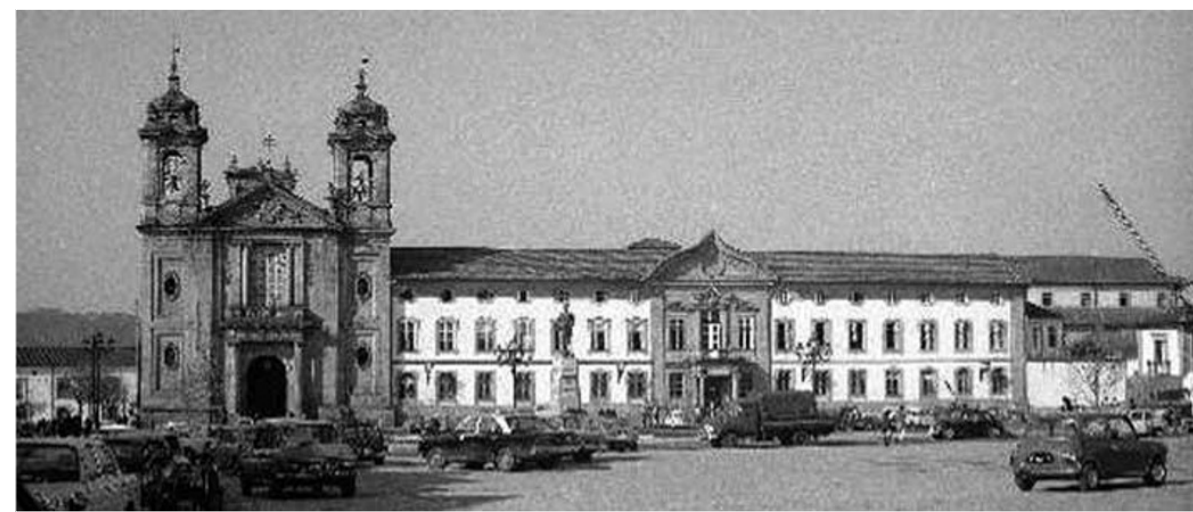

Figure I: Pópulo Church façade

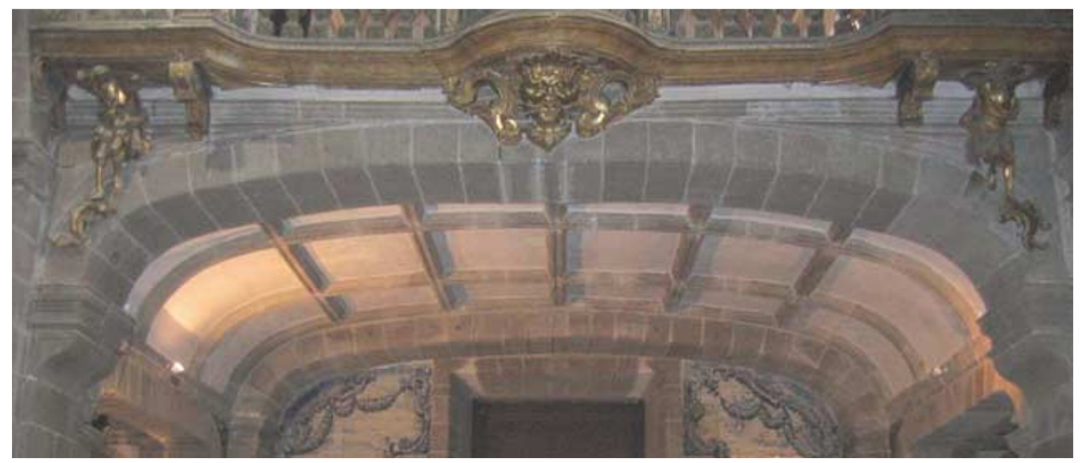

Figure 2: Upper-choir structure 
located between the main entrance of the church and the arch supporting the upper-choir balustrade, as recorded on a technical report sent to DREMN (Costa et al., 2000).

To better understand the structure under analysis, the upper-choir vault is described in detail with particular concern for its shape and materials. The vault is set between four arches: two main arches, referred to as A and B, and two secondary arches, referred to as $\mathrm{C}$ and $\mathrm{D}$. The church plan is illustrated in Figure 3 and shows the location of the arches. Arch A, Figures 2 and 4, represents the element supporting the balustrade and arch B, Figures 2 and 5, is the element over the main entrance of the church. Both arches are made of regular stone masonry, spanning approximately $9.70 \mathrm{~m}$ and are $5.60 \mathrm{~m}$ apart. Near the columns, the arches follow a narrow curved section, which opens towards the keystone. More than $2 / 3$ of the arch span follows an almost horizontal line.

The vault follows the line of the arches and it is made of regular stone masonry frames, each approximately $1.70 \times 1.70 \mathrm{~m}^{2}$, and it is filled in with redbrick masonry. On the sides, the vault lies upon two regular stone masonry arches with a free span of approximately $4.60 \mathrm{~m}$, referred to as arches $\mathrm{C}$ and $\mathrm{D}$ in Figure 3. In terms of damage, arch A exhibited vertical displacements with openings of joints at the keystone. The upper-choir vault also showed vertical displacements with openings of joints reaching almost $10 \mathrm{~mm}$ width, and surface warping with double inverted curvature. Arches B, C and $\mathrm{D}$ did not show evidence of any deformation. Conclusions from the technical inspection and diagnosis that were carried out concerning arches $\mathrm{C}$ and $\mathrm{D}$ can be found in Costa et al. (2000).

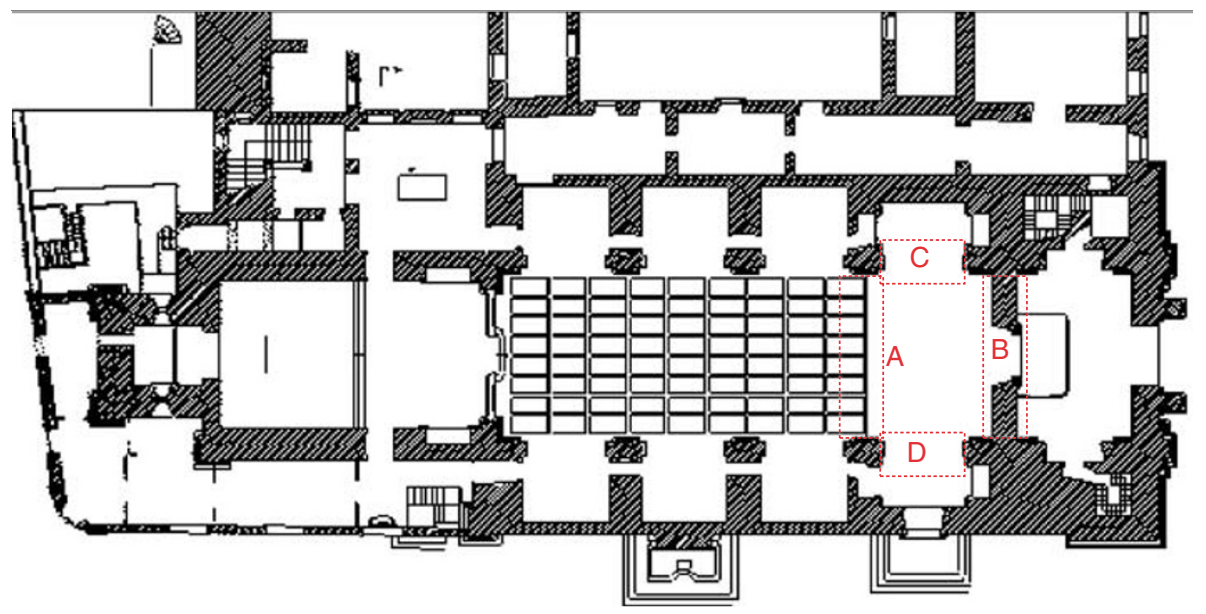

Figure 3: Church plan with the location of arches A, B, C and D
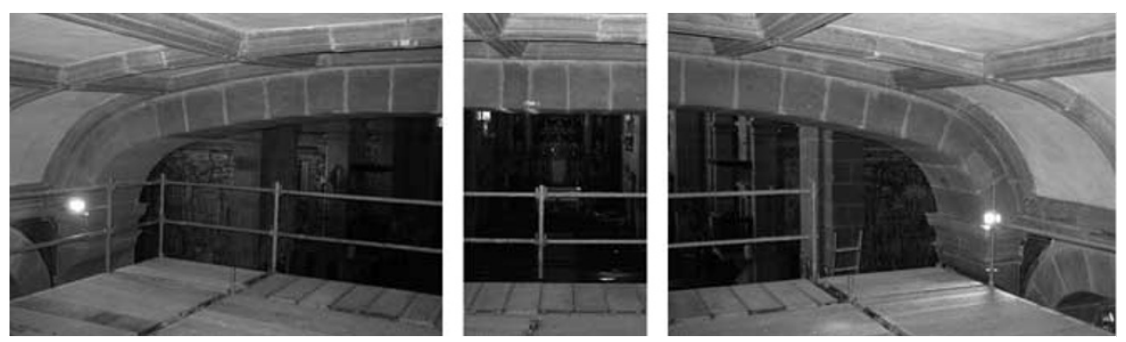

Figure 4: Façade of $\operatorname{arch} A$ 


\section{SEQUENCE OF THE STRUCTURAL INTERVENTION}

\section{Structural monitoring}

During the first stage of the structural intervention, the vault and arch A were monitored in order to detect possible displacements at the upper-choir structure and to verify if deformations were still occurring or had stabilised. As such, in July 2003, crack meters (Figure 6) were set at strategic spots of the vault intersections: joint openings or relevant cracks, namely on the central ribs and at the keystone of arch A façade. In order to help set the crack meters and taking the measurements, a scaffolding was assembled under the vault. Simultaneously, the distance between the main arches A and B (5.62 m) and the lateral arches C and D $(9.98 \mathrm{~m})$, as well as the vertical distance of several pre-defined points along the medium transverse line of the vault with respect to a fixed reference structure, were measured using a laser distance meter.

Weekly readings and measurements were made during July and August 2003. Afterwards, and for a monitoring period of a year and a half, readings and measurements were made monthly. The year and a half period was important to include both wet and dry seasons and different temperature conditions, in order to exclude cyclic weather causes that could justify the observed damage. The data collected during monitoring are crucial in determining the necessity of any structural renovation work, since repairs,
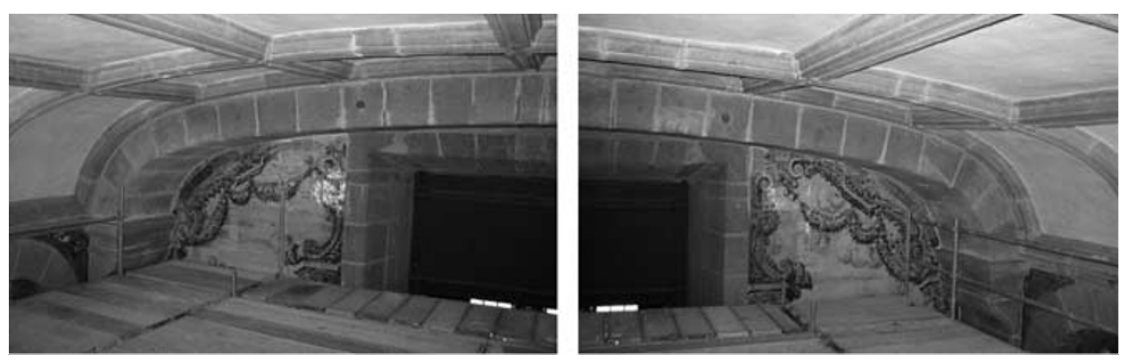

Figure 5: Façade of arch B

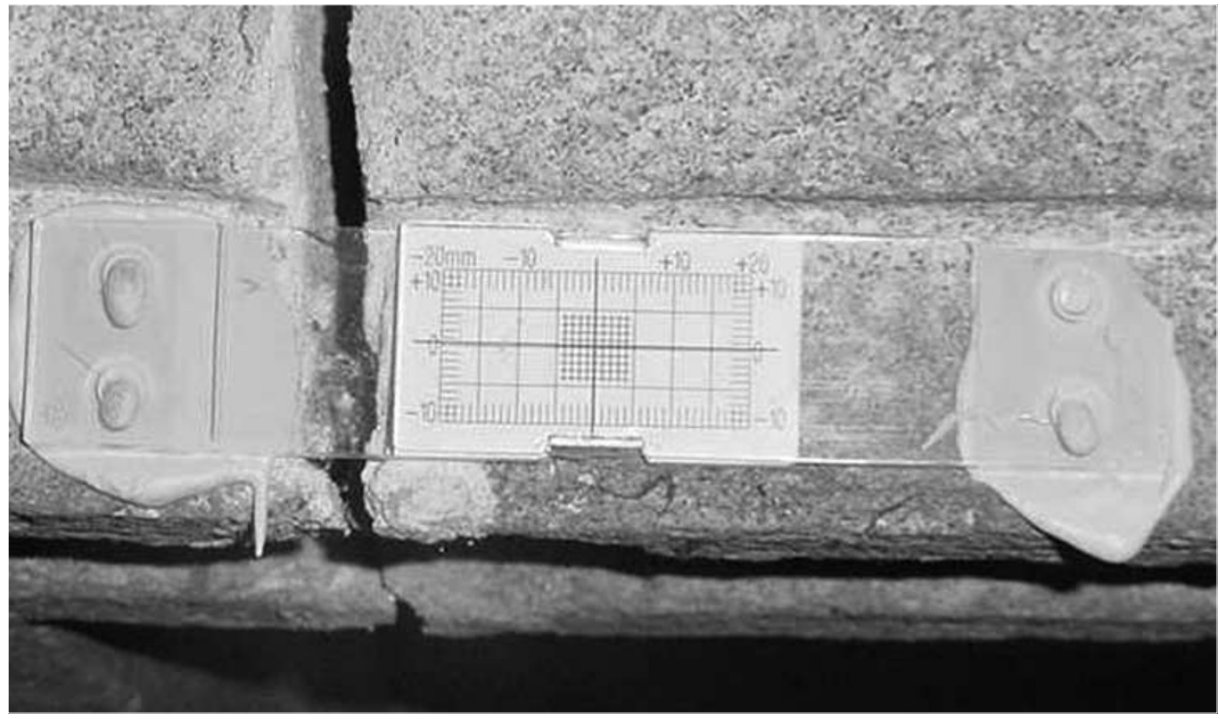

Figure 6: Crack meter on a stone frame of the vault 
strengthening procedures or structure consolidation works should not be performed while their causes still persist.

The data obtained showed that no changes had occurred during the monitoring period at the crack meters, nor significant changes in the distances between arches A and B, and between $\mathrm{C}$ and $\mathrm{D}$, and in the vertical distances to the vault control points.

\section{First action on the structure - Global strengthening}

Although the monitoring phase did not identify any active deformations, because of the current state of deformation of both arch A and the upper-choir vault, as well as the almost horizontal outline of these elements at the central area, a decision was made to strengthen the upper-choir vault.

Before undertaking the strengthening solution, some preliminary works took place to identify the structure of the vault, namely the material and the thickness. An inspection of the vault verified that inside the stone masonry frames, there was a 30-cm-thick shell made of redbrick elements (Figure 7). These and other preliminary actions identified the geometrical and material characteristics of the structure. For instance, the floor, made up of well-designed wooden boards, was supported by wooden joists set directly on the middle area of the vault and over a filling material of stones and gravel next to the set-up zones (Figure 8). It should be noted that both the removal and resetting of the wooden floor were included within the scope of works to be carried out at the upper-choir under DREMN's renovation programme.
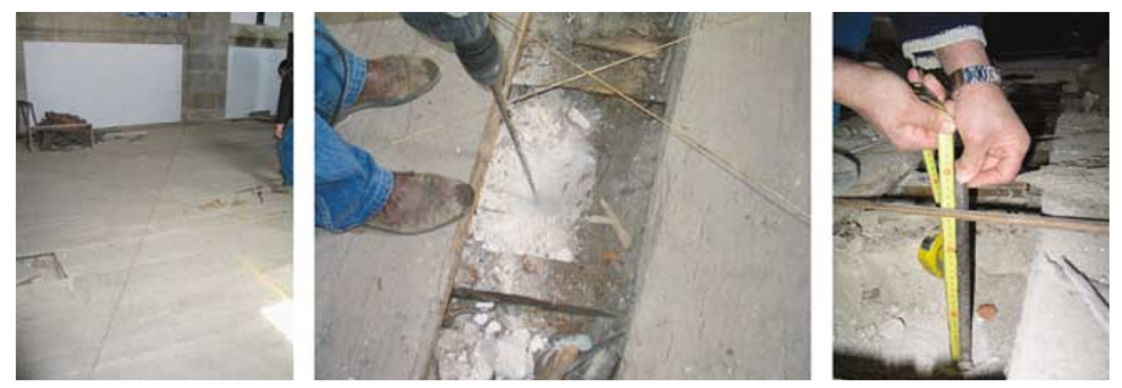

Figure 7: Inspection to the central part of the vault
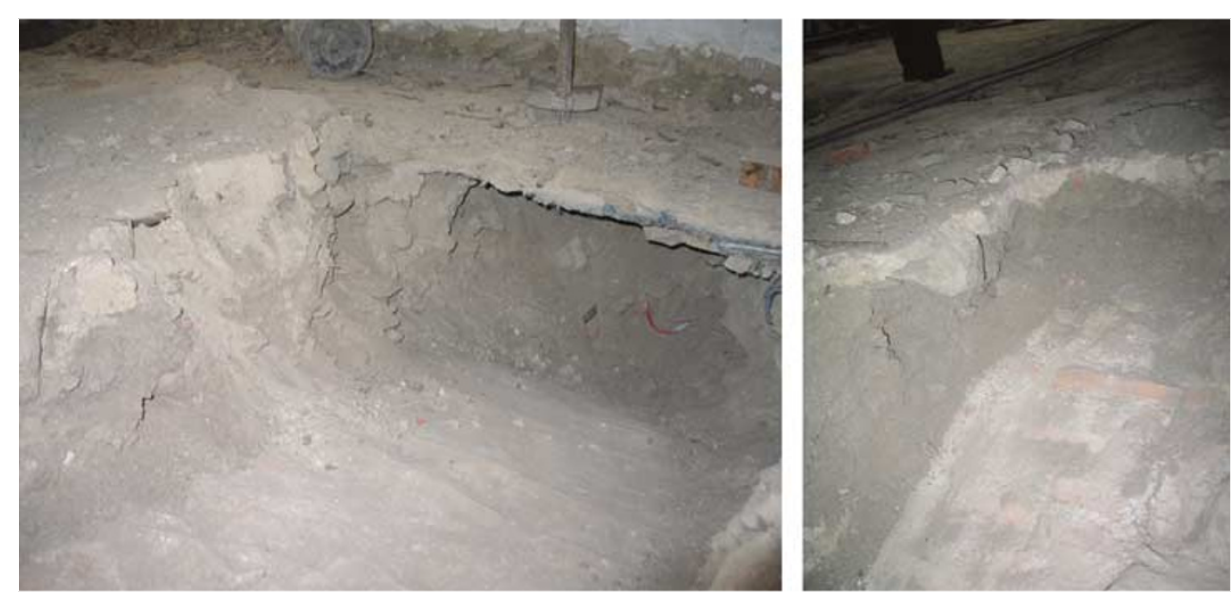

Figure 8: Vault barrel and fill material at the connection zones 
After analysing these data, the decision was made to design a steel structure to be set above the vault and under the wooden floor to suspend the vault through vertical ties anchored at the crossing points of the stone masonry frames. Figure 9 presents the drawing of the steel structure over the upper-choir plan. The structure would be fixed to the upper-choir side walls and would sustain any vertical displacements that might occur, thus securing the structural stability of the vault (Costa et al., 2004). The steel structure was designed considering the permanent load and a live load of $2 \mathrm{kN} / \mathrm{m}^{2}$, compatible with the proposed future use of this area that is intended only for restricted access.

Although this procedure seemed reversible and minimally intrusive, some physical limitations had to be overcome. In particular, the steel structure introduced major forces at the anchorage points on the walls, thus requiring thorough mechanical and structural investigation of these structural elements in order to verify if there was sufficient capacity to resist the anchorage forces. Although it appeared to correspond to good-quality regular masonry areas, the regular stone masonry was only used for covering masonry of inferior quality (Figure 10). Hence, a visual inspection would not be sufficient to assess the strength capacity of these zones and in situ tests had to be carried out (Roque and Lourenço, 2003).

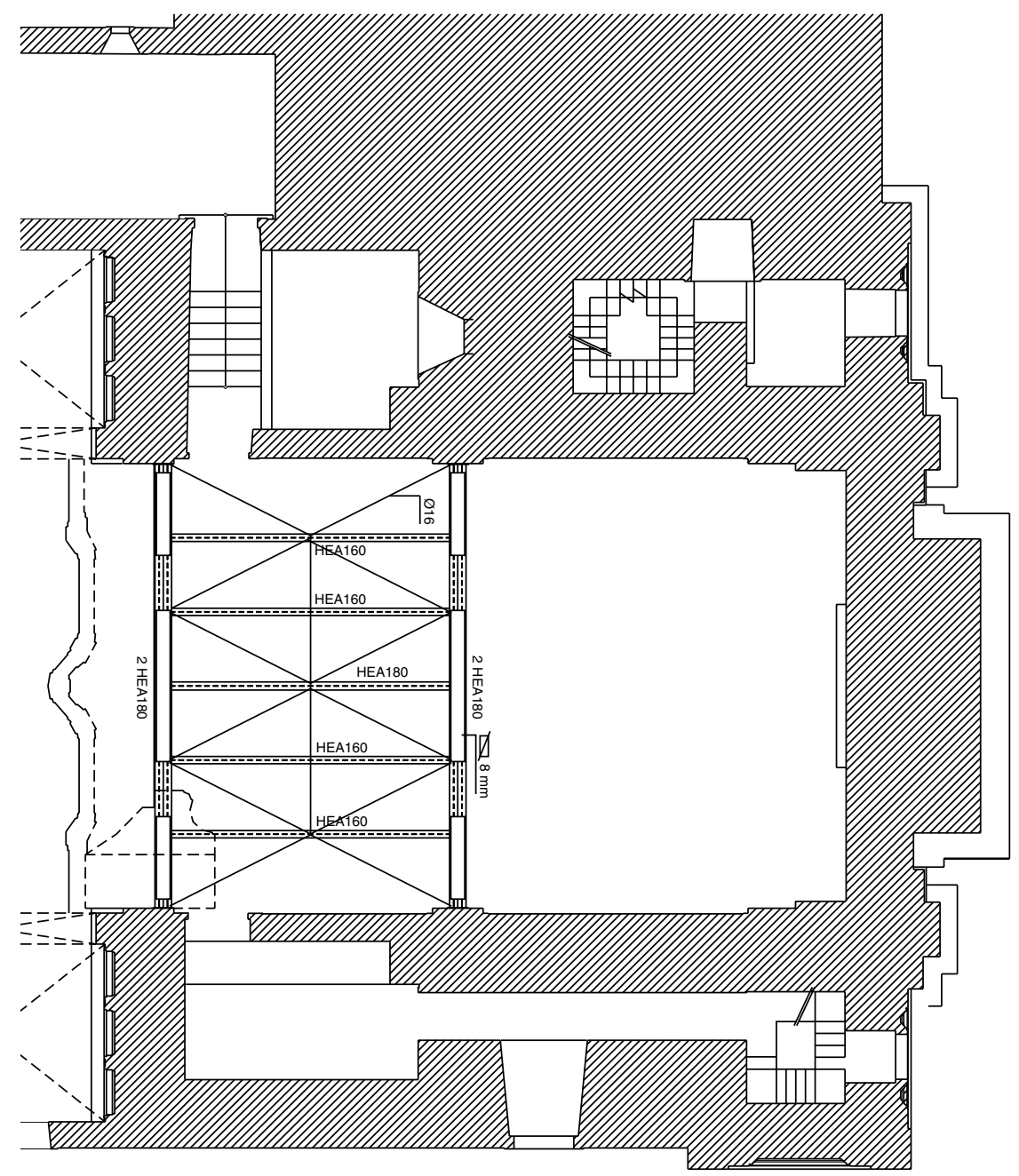

Figure 9: Upper-choir plan; strengthening steel structure 

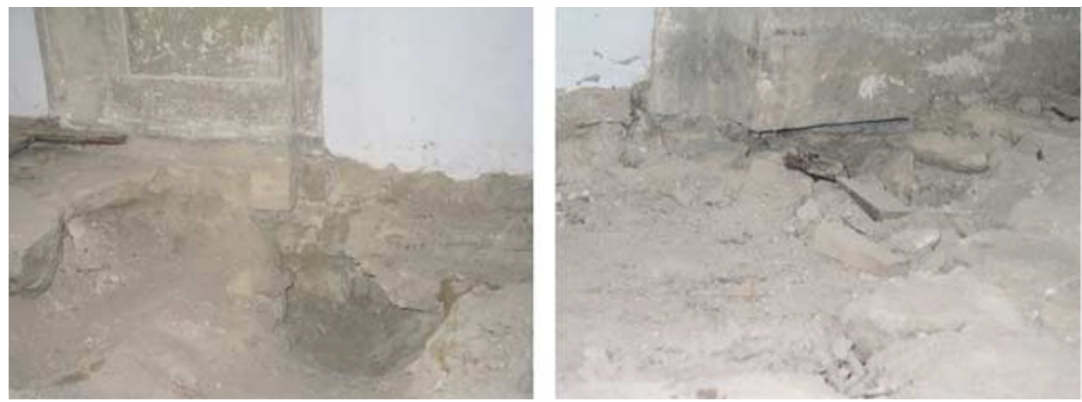

Figure 10: Faced regular stone masonry column at the level of the upper-choir pavement

Furthermore, the following physical limitations also had to be overcome:

- The pavement level would have to be lifted almost $16 \mathrm{~cm}$ above the current level.

- The existence of an ancient organ in precarious conditions (that could not be moved), placed against one of the upper-choir walls near the balustrade, made access difficult to one of the main anchorage areas of the steel structure. Despite considering the possibility of suspending the organ above the floor to set and anchor the steel members, this operation appeared to be quite difficult due to its delicate condition.

Facing such difficulties, a global strategy was considered based on two key outcomes. First, the monitoring of the vault and of arch A detected no active displacements on these two structures, that is the deformations were stabilised. Secondly, practice shows that despite its flat shape this kind of structure possesses a high strength capacity as long as no longitudinal movements are allowed, in particular at the set-up points. Because of the deformations that the structure had already experienced in the past, a decision was, however, made to perform a load test to confirm and support this qualitative judgment.

\section{Second action on the structure - Load test}

Regular stone or brick masonry structures show a good resisting capacity to compression forces compared with a brittle performance and low resisting capacity to tensile/flexural forces. The poor tensile capacity is not only due to the stone and brick material characteristics but also due to the composition of masonry structures; the result of single elements overlayed, creating joints, mostly dry, which work under compression and shear forces. Shear is the outcome of the combination of the friction forces and the installed compression forces along the joints. The tensile-resisting capacity of regular stone masonry structures is almost insignificant and results from the joints mortar tensile strength.

In particular, arch structures, designed to respond to compression forces, are a good example of structural elements to be built in masonry. In most cases, these elements are oversized, with a load capacity much higher than the one they were actually designed for. Based on these considerations and on the authors belief that the vault was able to resist a design live load of around $3.0 \mathrm{kN} / \mathrm{m}^{2}\left(1.5 \times 2.0=3.0 \mathrm{kN} / \mathrm{m}^{2}\right)$, a load test was performed to confirm this assumption. Moreover, such testing would allow registering the evolution of the deformations with the applied load and assessing the vaults structural performance.

To prepare the test, a scaffold was erected to create a working platform at the level of the inner surface of the vault and, at the same time, to create a passage tunnel for visitors coming from the church's main entrance. It was positioned so that its vertical elements 

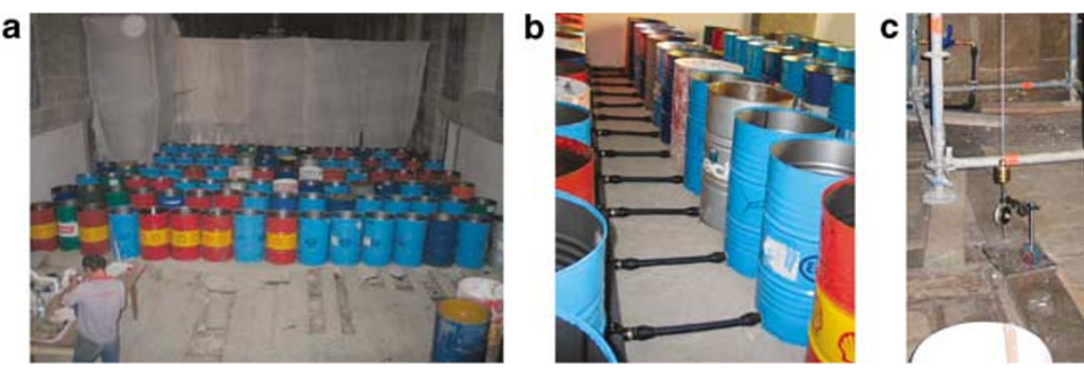

Figure I I: (a) Barrels positioning, (b) hydraulic network and (c) measurement equipment

were aligned with the intersection points of the granite frames, with the top of the vertical elements at approximately $1 \mathrm{~cm}$ from these points. With this procedure, the scaffolding structure acted also as an emergency prop in case any plastic deformation of the vault occurred.

During the tests, the load was applied by filling up 92 metal barrels with water with an average inner diameter of $58 \mathrm{~cm}$ and an average inner height of $86 \mathrm{~cm}$. The barrels were aligned on the upper-choir floor, as illustrated in Figure 11a.

To make the process easier and to guarantee a uniformly distributed load over the floor, the barrels were connected at the bottom using a hydraulic network (Figure 11b), connected to the municipal water supply system. A valve and a counter were set at the beginning of the piping system to control and record the water input, that is the actual load on the vault. To empty the tanks efficiently, the network was connected to two pipes with valves discharging directly into a rainwater collector in the square in front of the church's main entrance.

During the tests, the vault was monitored using a digital and analogical comparing equipment measuring the vertical displacements (Figure 11c) and the crack meters previously installed to monitor the openings of the joints. The control of the vertical displacements was performed at the intersection points of the vault masonry frames; steel threads were tied up to these points and kept straight through weights that were set against the cursors of the comparing devices fixed on the nave floor using heavy bases. This procedure allowed transmitting the vertical deformation of the vault to the comparing devices that recorded the displacements.

The test was performed for five load steps that corresponded to load values of $6,231 \mathrm{~kg}\left(91 \mathrm{~kg} / \mathrm{m}^{2}\right), 10,328 \mathrm{~kg}\left(150 \mathrm{~kg} / \mathrm{m}^{2}\right), 13,768 \mathrm{~kg}\left(200 \mathrm{~kg} / \mathrm{m}^{2}\right), 17,268 \mathrm{~kg}\left(251 \mathrm{~kg} / \mathrm{m}^{2}\right)$ and $20,081 \mathrm{~kg}\left(292 \mathrm{~kg} / \mathrm{m}^{2}\right)$. To check the apparatus, the first load step was divided into lower load steps. Some water leaks detected in the network connection terminals were repaired and the water level of the tanks was checked to compare it with the input water volume recorded by the counter. After concluding this procedure, the tanks were emptied and the test was reinitialised and the five load steps programme was followed.

After the last load step, the water level in every tank was registered, in order to assess the total load actually installed at the upper-choir floor, which was around $3 \mathrm{kN} / \mathrm{m}^{2}$. Between each load step, the values registered by the comparing devices were recorded. The highest value, almost $3 \mathrm{~mm}$, was registered at the vault central area. The crack meters were also continuously checked, but no visible displacements were detected.

The outcome analysis and, particularly, the total load versus the measured vertical displacement curves at two central points - the most significant registered points showed an almost linear performance, with an insignificant loss of stiffness without 
evidence of an imminent failure trend (Figure 12). In this analysis, the possible occurrence of an immediate failure without any 'plastic deformation' was safeguarded. On the other hand, the small vertical displacements registered, associated with the nonvisible openings of the monitored joints, confirmed that the load value of $3 \mathrm{kN} / \mathrm{m}^{2}$ is still within acceptable safety limits. Considering this new outcome, the strengthening solution proposed previously was abandoned and the intervention was reformulated.

\section{Third action on the structure - Final strengthening solution}

After the results of the load test, two possible actions were considered:

(a) restore the original conditions regarding the material on the vault (gravel and stones) to support the beams for the new wooden floor, without carrying out any structural repair or strengthening action or

(b) strengthen the extrados connections between the stones of the masonry frames before proceeding with procedure (a).

After careful analysis, and taking into account that most of the vault extrados was already uncovered and exposed, solution (b) was adopted.

The stones of the masonry frames were connected with inverted $\mathrm{U}$ or E-shaped 50-mm-width and 5-mm-thick stainless steel plates anchored to the stones with a delivery of around $50 \mathrm{~mm}$. This procedure allowed strengthening of the upper face of the stone masonry frames as shown in Figure 13. The U-shaped plates were used to connect two stones and the E-shaped to connect three stones, connecting one or two joints,

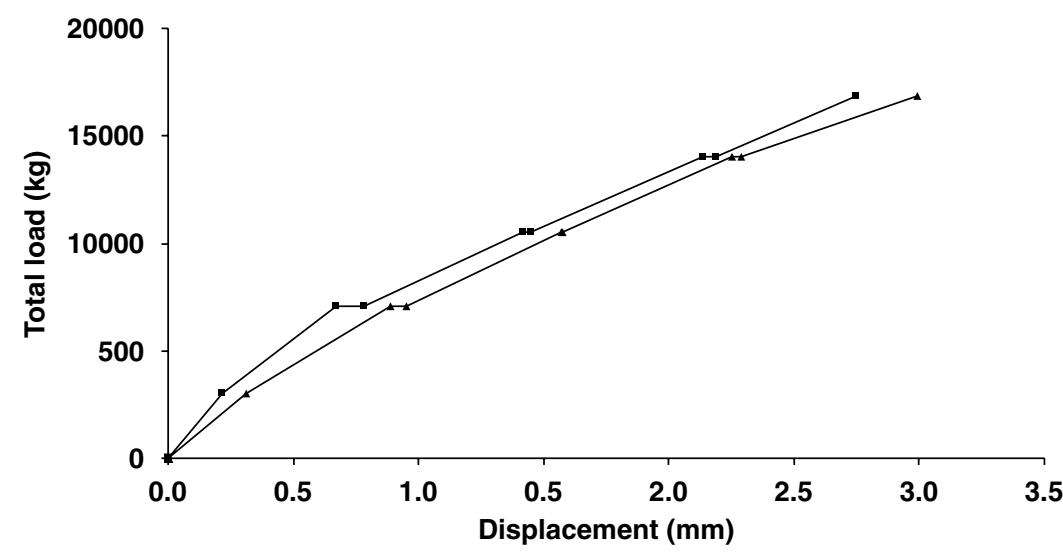

Figure 12: Load versus vertical displacement curve
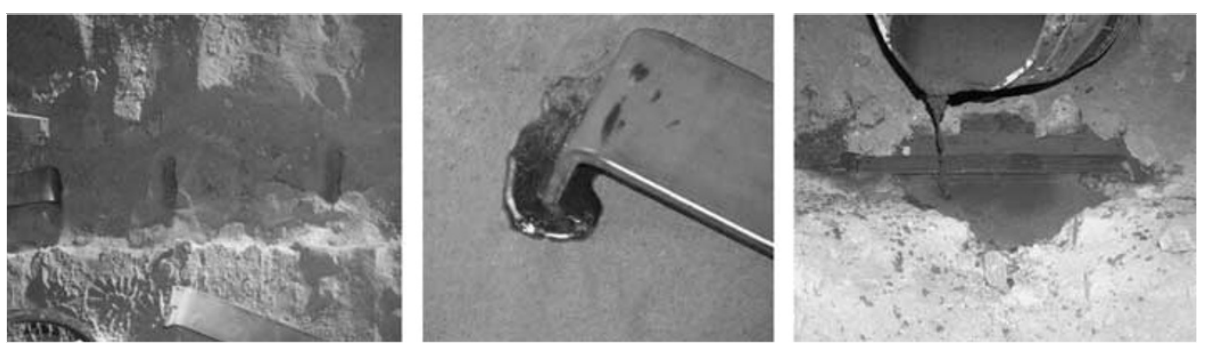

Figure 13: Stainless steel plates anchored to the stones 
respectively. E-shaped plates were used in small-sized stones where joints were too close to one another. Holes were made on the stones and the plates were anchored by the traditional process of melted lead. Where the stones surface was irregular, SikaGrout mortar was placed between the plate and the stones after the above procedure to enable uniform contact between both elements.

It should be stressed that the strengthening performed on the extrados will prevent flexural deformation of the vault on the sides, and will contribute to increase the stiffness of the vaults and, consequently, reduce the ability of the structure to deform. On the other hand, by including the strengthening of the vault central area, this procedure provides a more uniform behaviour and, therefore, a better global performance of the structure, following a minimum intervention procedure, as recommended by international recommendations (ICOMOS, 2001).

Finally, the joints that were opened were sealed using nonretractile mortar compatible with the vault masonry (Luxán and Dorrego, 2002). In the future, this procedure will also allow controlling further displacements that would occur at the vaults.

\section{FINAL CONCLUSIONS}

This paper describes the renovation works performed at the upper-choir of the Pópulo Church in Braga, Portugal. This was a technical consultancy work requested by DREMN to NCREP to help decide which kind of intervention would be suitable to repair the damage found at the structure: deformation of the upper-choir vault with cracking and opening of the joints visible at the inner face.

As such, after monitoring the vault and confirming the stability of the observed deformations, crack gauges positioned at key points for a year and a half period had not detected any displacement, a strengthening structure was designed, consisting of a steel structure to be installed above the vault and connected to the vault on the stone masonry frames intersection points through vertical ties in order to sustain any future vertical movement of the vault. The implementation of this solution, however, presented some obstacles. Considering this analysis, it was then decided to perform a load test on the upper-choir vault, in order to verify the capacity of the structure to resist the design live load that would be compatible with the predictable future use of this area. In fact, the test showed the good performance of the vault for a live load of $290 \mathrm{~kg} / \mathrm{m}^{2}$, with a $3 \mathrm{~mm}$ maximum displacement, largely compatible with the use of this space conceived for restrained access.

The first strengthening solution was then abandoned and a minimum intervention was suggested and implemented. It consisted of anchoring stainless steel plates on the upper face of the masonry frames in order to connect the stones together. This procedure reduced the possibility of structural deformation and guaranteed a more uniform performance of the vault, due to a better connection between the frame stone elements.

Finally and as a general conclusion, this paper shows the peculiarities of the intervention works on old constructions. Despite being previously planned and projected according to the available knowledge of the existing structure, during the preparation and implementation of the intervention procedures they may suffer relevant modifications that must be seen as being part of the whole intervention process.

\section{Acknowledgements}

The authors wish to express their gratitude to DREMN and to Eng. Filipe Ferreira from the company Augusto de Oliveira Ferreira Lda. 


\section{References}

Costa, A., Arêde, A. and e Costa, C. (2000) Relatório de Inspecção ao Coro Alto da Igreja do Pópulo. Technical Report, Construction Institute, Faculty of Engineering of Porto University, Porto, Portugal.

Costa, A., Guedes, J. and e Paupério, E. (2004) Relatório de Intervenção Estrutural no Coro Alto da Igreja do Pópulo; Abóbada e Arco Principal. Technical Report, Construction Institute, Faculty of Engineering of Porto University, Porto, Portugal.

ICOMOS (2004) Recommendations for the Analysis, Conservation and Structural Restoration of Architectural Heritage. International Council on Monuments and Sites.

Luxán, P. and Dorrego, F. (2002) Morteros Antíguos y la Intervención el Patrimonio. A Intervenção no Património Práticas de Conservação e Reabilitação pp. 183-191 — FEUP.

Roque, J.C.A and Lourenço, P.B. (2003) Caracterização Mecânica de Paredes Antigas de Alvenaria. Um Caso de Estudo no Centro Histórico de Bragança. Engenharia Civil, 17, pp. 31-42. 